\title{
Effect of Composition on the Mechanical Properties and Wear Resistance of Low and Medium Carbon Steels with a Biomimetic Non-Smooth Surface Processed by Laser Remelting
}

\author{
Geng Chang ${ }^{1,2}$, Ti Zhou ${ }^{1,3, *}$, Hong Zhou ${ }^{1,2}$, Peng Zhang ${ }^{1,2}$, Siyuan Ma ${ }^{1,2}$, Benfeng Zhi ${ }^{1,2}$ and \\ Siyang Wang 1,2 \\ 1 Key Laboratory of Automobile Materials, Jilin University, Ministry of Education, Changchun 130025, China; \\ changgengjlu@163.com (G.C.); qingqingzijinyo@sina.com (H.Z.); pengzhangjlu@sina.com (P.Z.); \\ masiyjlu@126.com (S.M.); zhibf17@163.com (B.Z.); siyangwangjlu@163.com (S.W.) \\ 2 School of Material Science and Technology, Jilin University, Changchun 130025, China \\ 3 School of Mechanical Science and Aerospace Engineering, Jilin University, Changchun 130025, China \\ * Correspondence: changgeng17@mails.jlu.edu.cn
}

Received: 19 November 2019; Accepted: 18 December 2019; Published: 24 December 2019

\begin{abstract}
To study the effect of laser biomimetic treatment on different material compositions, five kinds of steels with different carbon element contents were studied by laser remelting. The characteristics (depth, width), microstructure, hardness, tensile properties, and wear resistance of the samples were compared. The results show that when the laser processing parameters are fixed, the characteristics of the unit increase with an increase of carbon element content. Moreover, the hardness of the unit also increases. Compared with the untreated samples, when the carbon content is $0.15-0.45 \%$, the tensile strength of the laser biomimetic samples is higher than that of the untreated samples. For the biomimetic samples with different carbon content, with an increase of carbon content, the tensile strength increases first and then decreases, while the plasticity of the biomimetic samples decreases continuously. The bionic samples have better wear resistance than that of the untreated samples. For bionic specimens with different carbon elements, wear resistance increases with an increase of carbon element content.
\end{abstract}

Keywords: composition; laser bionic unit; tensile properties; wear resistance

\section{Introduction}

Natural organisms live in harsh and complex environments for long periods, so their body surfaces must possess a strong ability to resist external damage. A non-smooth morphology, non-smooth structure, and different material compositions on the surface of the organism are typical biological coupling characteristics [1-5]. Various non-smooth features provide an organism with an appropriate combination of strength and toughness and play a unique role in resisting external alternating stress or direct damage. For example, dragonfly wings $[6,7]$ are often in a vibrational state without failing, which is the result of the collaborative effect of the wing surface's grid shape and the wing vein's sandwich structure composed of multiphase materials. The desert scorpion [8] has been subjected to the erosion by sandstone permanently without damage, which is the result of the collaborative effect of its non-smooth surface and multiple layers of soft connective tissue under the skin; shellfish [9-11] have been eroded by seawater frequently without crack initiation, which is the result of their non-smooth surface composed of an alternating soft and hard structure and the coupling effect of the composite materials. Thus, inspired by the coupling characteristics of the surfaces of organisms, constructing 
a bionic non-smooth structure on the surface of mechanical parts to obtain specific properties has become a new surface modification method.

Laser remelting treatment [12-15], as a new technology, can be combined with coupled bionics to offer a new approach for manufacturing bionic non-smooth structures. In this process, a high energy laser beam irradiates the surface of the workpiece, making the laser radiation region of the workpiece rapidly melt. Then, the region is quickly solidified via heat conduction from the substrate, so the obtained microstructure is different from the matrix, and when the selected laser processing parameters are appropriate, the grain will be refined. The material's hardness is also much improved based on the pattern [16-18]. In this way, the non-smooth bionic structure with soft and hard phases is processed on the surface. Among these structures, the hard structure processed by laser fusion is called the bionic unit [19].

Previous studies [20-23] have shown that the improvement of material properties is closely related to the biomimetic unit. Materials with non-smooth structural biomimetic units have good wear resistance and fatigue resistance. The properties of the biomimetic unit are closely related to their composition, the microstructure of their matrix material, and their laser processing parameters. For example, Meng [24] studied the unit microstructure and thermal fatigue resistance of different kinds of die steel after laser biomimetic treatment. Zang [25] compared the microstructure and mechanical properties of $\mathrm{H} 13$ steel with different microstructures after laser biomimetic treatment. At present, the effect of the material composition on laser biomimetic treatment is rarely discussed in the literature. Therefore, in this paper, the low and medium carbon steels commonly used in industry were chosen as the research object, and we studied the influence of carbon content on the characteristics, microstructure, and mechanical properties of the bionic unit by machining the strip bionic unit on its surface. Finally, the wear experiments of samples with different carbon content were demonstrated. The purpose of this study is to provide a reliable theoretical reference for laser remelting strengthening of different carbon steel parts in actual industrial production and to serve industrial production practices.

\section{Experimentation}

\subsection{Materials}

Samples of 15 steel, 25 steel, 35 steel, 45 steel, and 55 steel with carbon content of $0.15 \%, 0.25 \%$, $0.37 \%, 0.45 \%$, and $0.58 \%$, respectively, were selected. The matrix samples are represented by A1, A2, A3, A4, and A5, respectively, and their chemical components are shown in Table 1. Laser biomimetic samples are represented by LR-A1, LR-A2, LR-A3, LR-A4, and LR-A5.

Table 1. The compositions of the samples (wt.\%).

\begin{tabular}{ccccccc}
\hline Groups & C & Si & Mn & S & P & Fe \\
\hline A1 & 0.15 & 0.11 & 0.28 & $<0.01$ & $<0.01$ & Bal \\
A2 & 0.25 & 0.21 & 0.53 & $<0.01$ & $<0.01$ & Bal \\
A3 & 0.37 & 0.18 & 0.61 & $<0.01$ & $<0.01$ & Bal \\
A4 & 0.45 & 0.20 & 0.55 & $<0.01$ & $<0.01$ & Bal \\
A5 & 0.58 & 0.25 & 0.75 & $<0.01$ & $<0.01$ & Bal \\
\hline
\end{tabular}

\subsection{Experimental Methods}

The wear samples were cut into the samples to be processed (with a volume size of $20 \times 30 \times$ $6 \mathrm{~mm}^{3}$ ) using an electric spark machine (DK7732, Huadong Group, Hangzhou, China), and the samples were processed successively with waterproof abrasive paper of different granularities to remove the traces of wire cutting. Then, an ultrasonic cleaner was used to clean the samples, thereby removing the residual oil and debris on the surface of the sample to achieve a smooth and clean surface. 
A bionic strip specimen was fabricated using a solid-state pulsed Nd: YAG laser with a wavelength of $1.064 \mu \mathrm{m}$ and maximum output power of $500 \mathrm{~W}$. The processing schematic diagram is shown in Figure 1. The laser processing parameters are shown in Table 2.
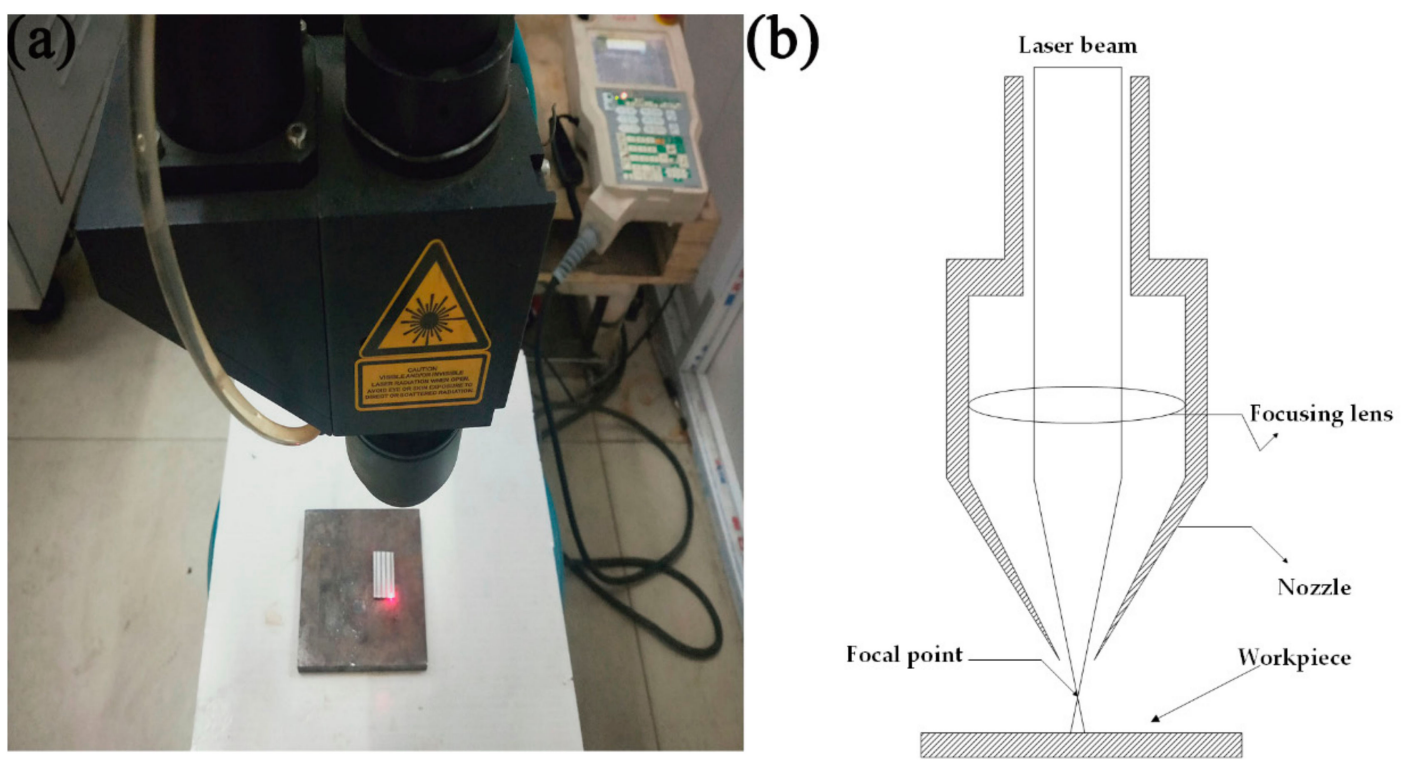

Figure 1. The schematic diagram of laser bionic processing.

Table 2. Laser processing parameters.

\begin{tabular}{ccccc}
\hline $\begin{array}{c}\text { Energy } \\
(\mathbf{J})\end{array}$ & $\begin{array}{c}\text { Pulse Duration } \\
(\mathbf{m s})\end{array}$ & $\begin{array}{c}\text { Frequency } \\
(\mathbf{H z})\end{array}$ & $\begin{array}{c}\text { Scanning Speed } \\
(\mathbf{m m} / \mathbf{s})\end{array}$ & $\begin{array}{c}\text { Beam Diameter } \\
(\mathbf{m m})\end{array}$ \\
\hline 16.88 & 8 & 5 & 1 & 1.59 \\
\hline
\end{tabular}

The sample was cut in the direction perpendicular to the incident direction of the laser using an electric spark machine. The cross-section was sequentially milled and polished. Pickling was carried out using a $4 \%$ nitric acid solution. Characterizations of the cross-section of the unit were carried out using an optical microscope (Zeiss, Axio Image A2m, Oberkochen, Germany). The microstructure of the unit and the substrate were observed using an electron scanning microscope (Zeiss, EV018, Oberkochen, Germany). The X-ray diffractometer (Rigaku D/Max 2500PC, Tokyo, Japan) was used for phase analysis.

Microhardness testing was performed on a microhardness tester (HVS-1000A, Beijing, China). The load was $1.962 \mathrm{~N}$, and the holding time was $10 \mathrm{~s}$. A schematic diagram of the hardness is shown in Figure 2.

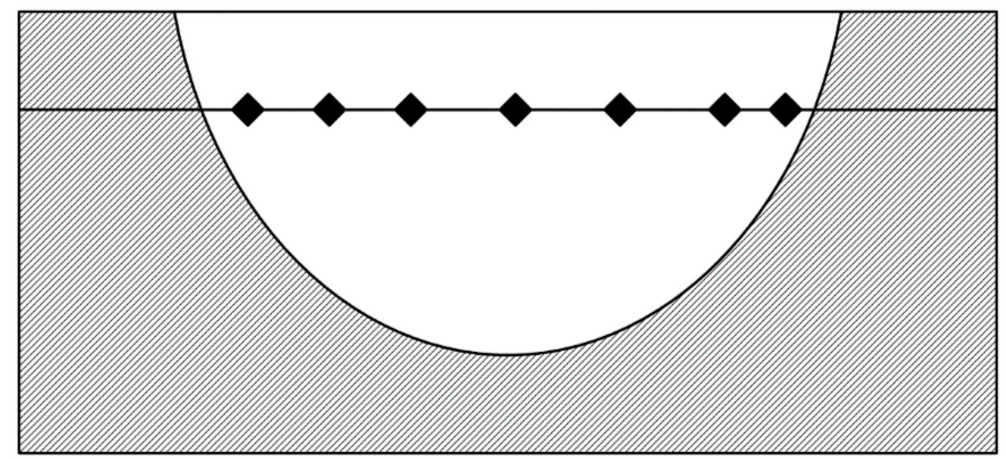

Figure 2. The position of the hardness measurement points. 
The tensile test was carried out on a hydraulic servo test machine (MTS 810, MTS Systems Corporation, Eden Prairie, MN, USA) at room temperature and the crosshead speed is $1 \mathrm{~mm} / \mathrm{s}$. Figure $3 \mathrm{a}$ shows the dimensions of the tensile specimen after laser bionic treatment. Three test specimens for each set were tested and averaged as the final result. After the test, the tensile fracture morphology for all samples were analyzed.

(a)

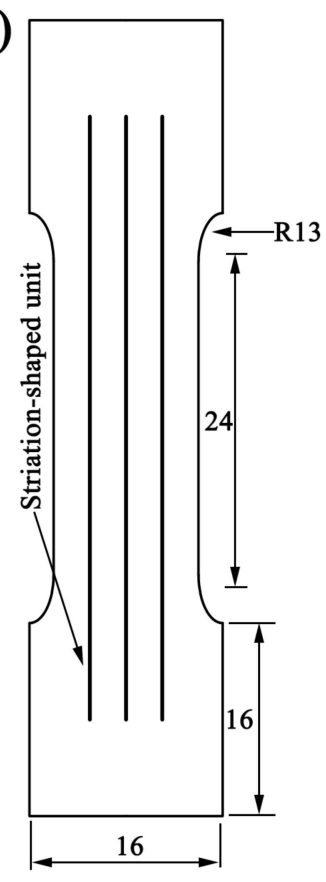

(b)
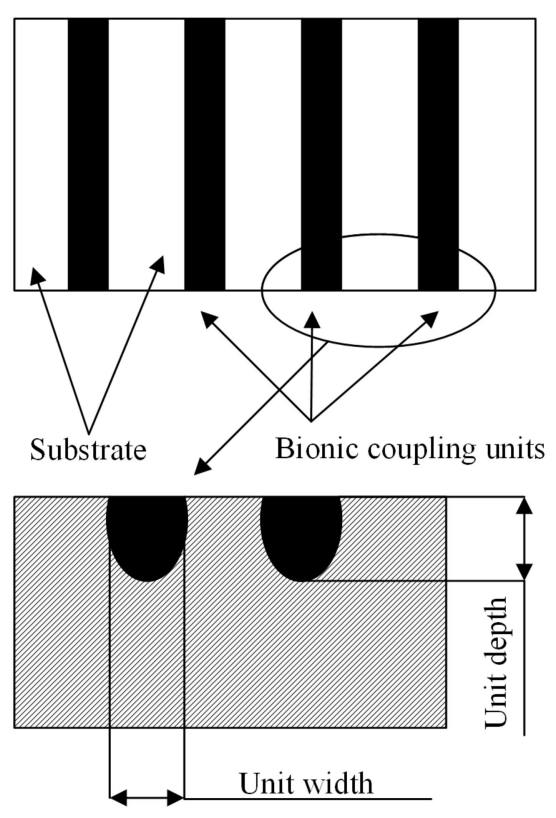

Figure 3. The bionic specimens used for (a) tensile and (b) wear testing.

Figure $3 b$ shows a schematic of the wear sample after laser bionic treatment. The schematic of the reciprocating sliding wear testing machine developed by the laboratory is shown in Figure 4 . During the experiment, the friction pair was fixed, and the sample located in the card slot was linearly reciprocated. The friction pair material is made of quenched gray iron $(800 \mathrm{HV})$, the eccentric speed is $690 \mathrm{r} / \mathrm{min}$, the wear time is $600 \mathrm{~min}$, and the load is $100 \mathrm{~N}$. All experiments were carried out at room temperature under dry conditions.

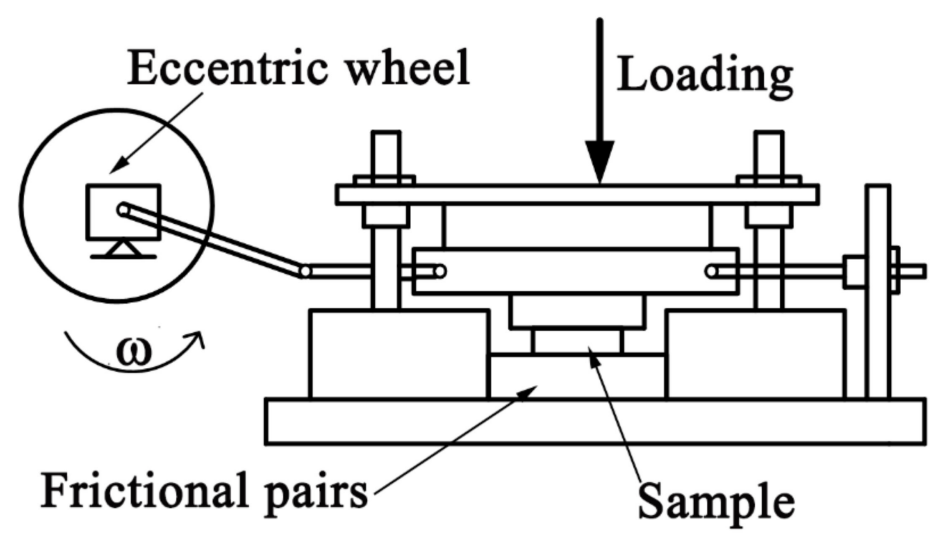

Figure 4. Schematic of the siding wear tester.

Before and after the wear test, the samples were cleaned with an ultrasonic cleaner, dried for half an hour, and then weighed before and after wear by an electronic balance (FA2400, Shanghai jinmin instrument equipment co. LTD, Changshu city, China); then, the weight loss was calculated. Each 
experiment was repeated three times, and the final results were averaged. Finally, the wear surface morphology was observed with a surface profiler (NT9100, Brock, Germany).

\section{Results and Discussion}

\subsection{Cross-Section Morphology and Size of the Biomimetic Units with Different Carbon Content}

Figure 5 shows the cross-sectional morphology of biomimetic unit with different carbon content. It can be seen that the cross-sectional morphology is parabolic, and the unit is composed of two parts: One part is a fusion zone with a bright white color, and the other part is a heat-affected zone (HAZ) in contact with the matrix. Table 3 lists the cross-sectional dimensions of the bionic unit with different carbon contents. It can be concluded from Figure 5 and Table 3 that when the laser processing parameters are the same, as the carbon content increases, the unit characteristics are also increased. The unit characteristics are mainly related to the laser processing parameters and the thermophysical properties of the material [26]. When the laser processing parameters are the same, the thermal conductivity is the determining factor of the unit's characteristics. For carbon steel materials, thermal conductivity increases as the carbon content increases. A material with high thermal conductivity propagates heat at a faster rate, and its fusion zone is wider and deeper. The unit characteristics with different carbon content show this rule.
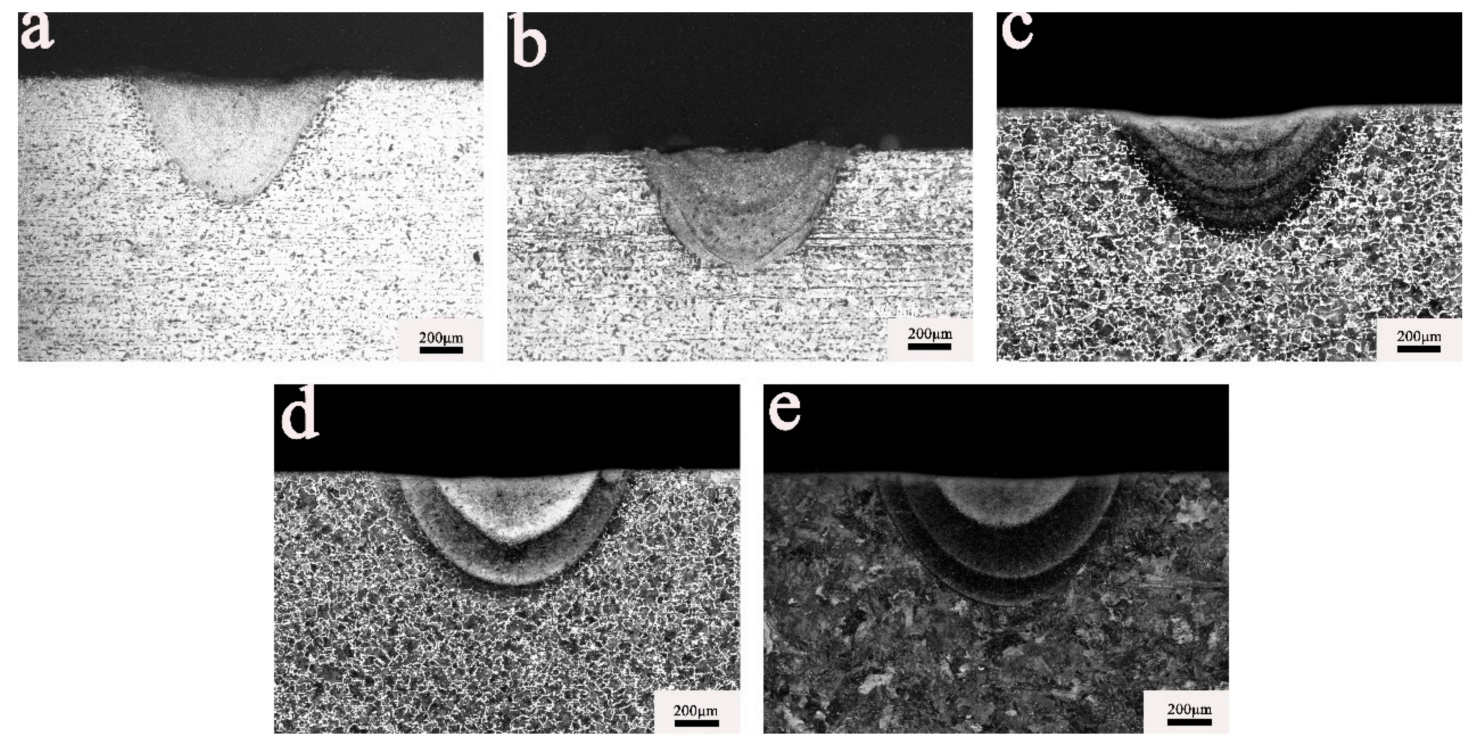

Figure 5. The cross-section of the biomimetic units: (a) LR-A1, (b) LR-A2, (c) LR-A3, (d) LR-A4, and (e) LR-A5.

Table 3. Unit characteristics of different materials.

\begin{tabular}{ccc}
\hline Groups & Unit Width $(\mu \mathrm{m})$ & Unit Depth $(\mu \mathrm{m})$ \\
\hline LR-A1 & 947.30 & 543.32 \\
LR-A2 & 1116.43 .84 & 579.24 \\
LR-A3 & 1241.64 & 607.29 \\
LR-A4 & 1265.4 & 663.37 \\
LR-A5 & 1346.02 & 726.47 \\
\hline
\end{tabular}




\subsection{Microstructure and Phase Composition of Different Carbon Content Matrixes and Bionic Samples}

\subsubsection{The Microstructure of the Matrix}

Figure 6a-e shows the microstructure of the matrix materials. It can be seen that the matrix structure of the five materials is the same, consisting of pearlite and ferrite; with an increase of carbon content, the ferrite content decreases, and the pearlite content increases.
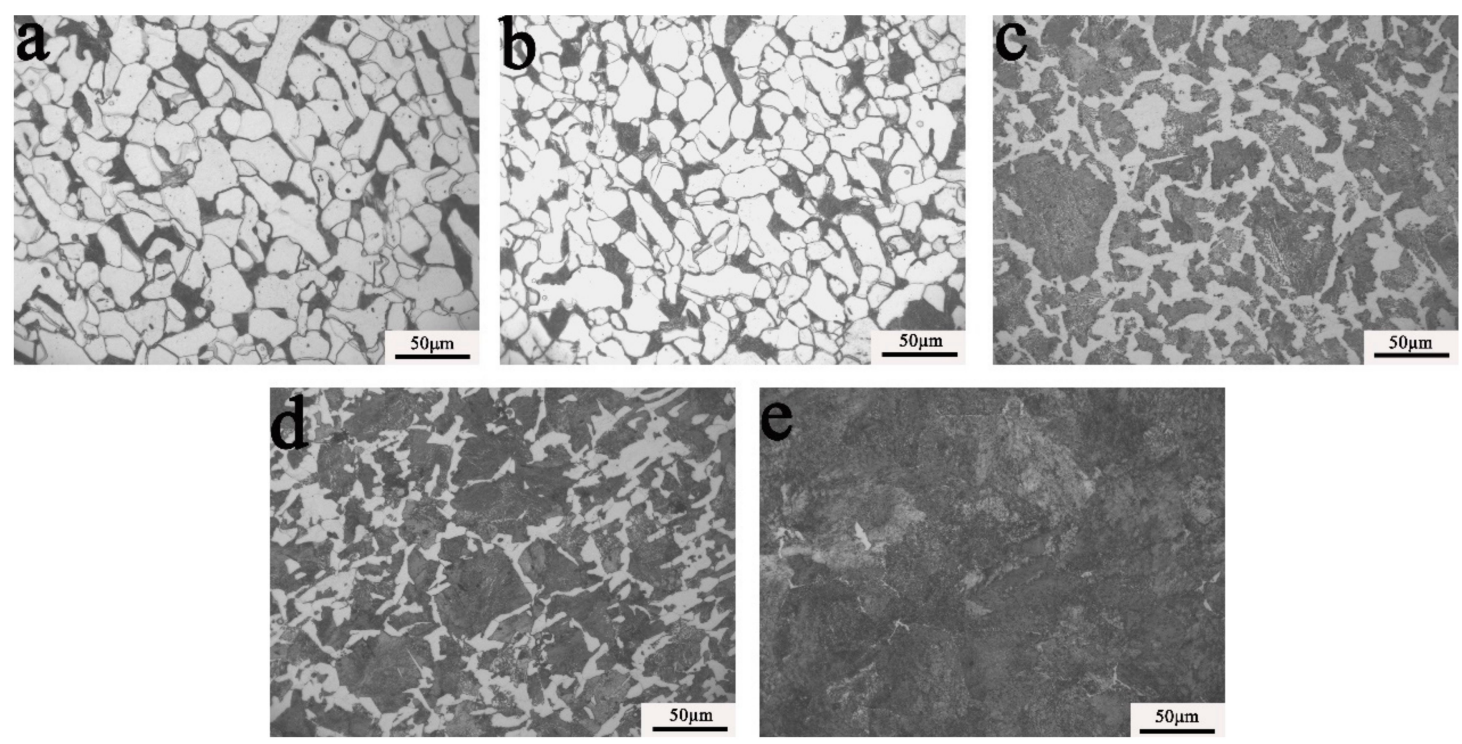

Figure 6. The microstructure of base material samples: (a) A1, (b) A2, (c) A3, (d) A4, and (e) A5.

\subsubsection{The microstructure of the unit}

Figure 7a-e shows the microstructure of the unit remelting zone of the laser biomimetic sample. Although the carbon content of the base material is different, the microstructure of the laser fusion zone is the same (which is composed of lath martensite and plate martensite). With an increase of carbon content, the content of the plate martensite gradually increases, and the content of lath martensite decreases. This is due to the different carbon content of the material.
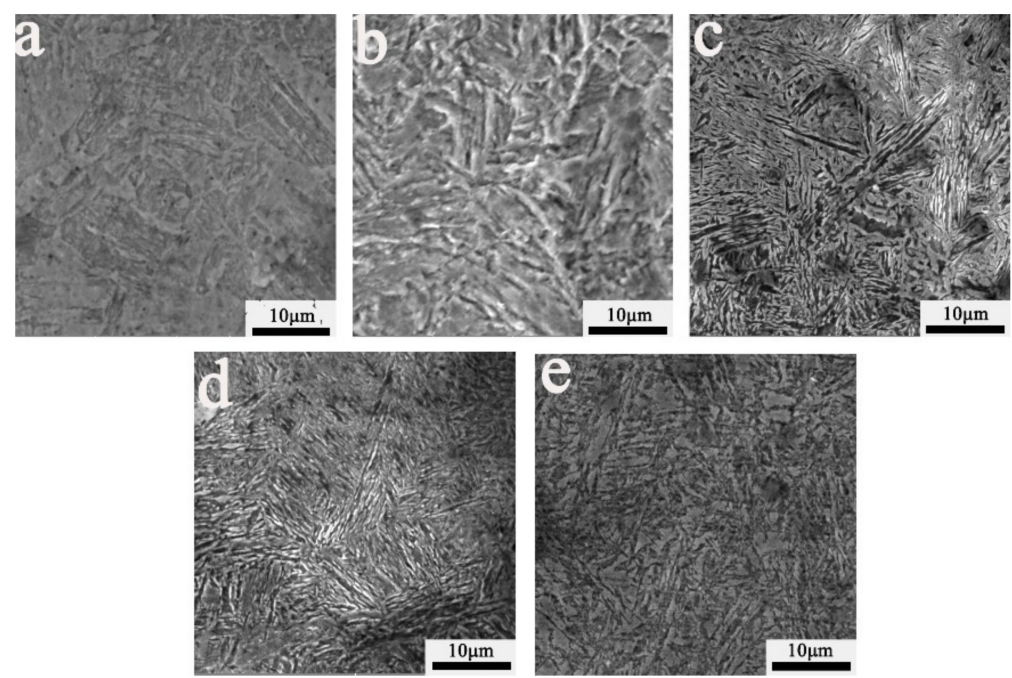

Figure 7. The microstructure of remelting zone of biomimetic unit: (a) LR-A1, (b) LR-A2, (c) LR-A3, (d) LR-A4, and (e) LR-A5. 


\subsubsection{Phase Analysis}

Figure 8a-e shows a comparison of the XRD between the matrix (A1-A5) and the biomimetic unit (LR-A1-LR-A5), and Figure 8f shows an XRD comparison diagram of the biomimetic unit (LR-A1-LR-A5). The results show that the main phase of the matrix is ferrite, and the phase of the laser biomimetic unit is martensite.
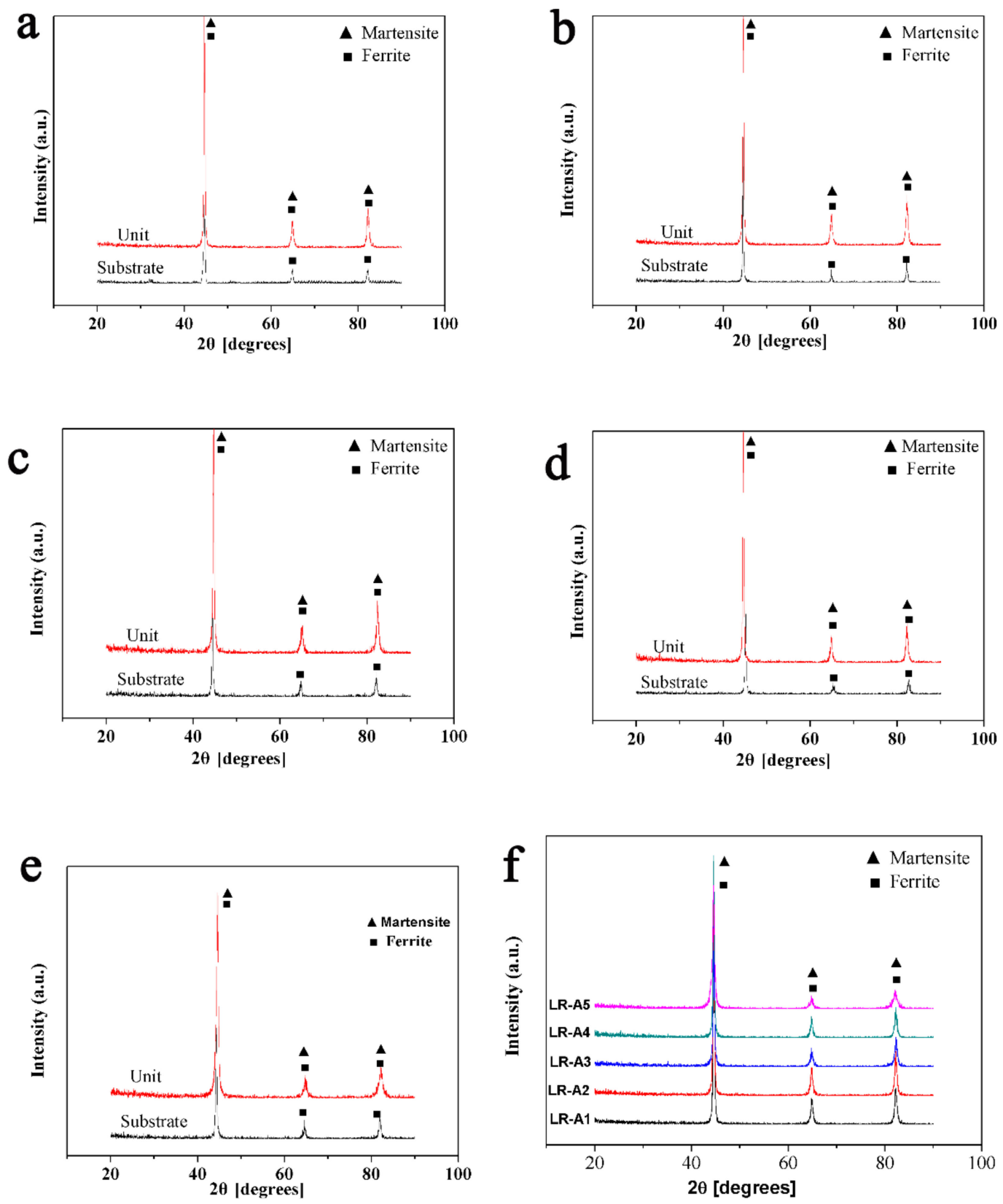

Figure 8. X-ray diffraction profiles of the biomimetic units and matrixes: (a) A1, (b) A2, (c) A3, (d) -A4, (e) A5; (f) comparative diffraction curves of LR-A1-LR-A5.

At the same time, Jade was used to analyze the half-height and width of the diffractive peak (FWHM) of the matrix and unit with different carbon content. The results show that the FWHM of the matrix materials are A1: $0.140^{\circ}, \mathrm{A} 2: 0.219^{\circ}, \mathrm{A} 3: 0.239^{\circ}, \mathrm{A} 4: 0.249^{\circ}$, and A5: $0.300^{\circ}$; the laser biomimetic 
samples' FWHM is $0.239^{\circ}, 0.243^{\circ}, 0.282^{\circ}, 0.286^{\circ}$, and $0.519^{\circ}$. The FWHM of the bionic unit of the same material is larger than that of the matrix material. Here we use Scherrer's formula [27]:

$$
D=\frac{K \lambda}{\beta \cos \theta},
$$

where $\mathrm{D}$ is the grain size, $\mathrm{K}$ (K value is 0.89 ) is the Scherrer constant, $\lambda$ is the wavelength of the $\mathrm{X}$-ray, $\beta$ is the full width at half maximum, and $\theta$ is the Bragg diffraction angle. It can be seen that under the same testing conditions, the grain size of the unit has been refined to different degrees, and the order of the grain size of the unit is LR-A5 $(67 \mathrm{~nm})<$ LR-A4 $(121 \mathrm{~nm})<$ LR-A3 $(123 \mathrm{~nm})<$ LR-A2 $(143 \mathrm{~nm})<$ LR-A1(145 nm).

\subsection{Mechanical Properties of Varying the Carbon Content Matrix and Bionic Samples}

\subsubsection{Microhardness of Matrix and Unit}

The microhardness of the base materials A1, A2, A3, A4, and A5 are $126 \mathrm{HV}, 176 \mathrm{HV}, 250 \mathrm{HV}$, $270 \mathrm{HV}$, and $320 \mathrm{HV}$, respectively. Figure $9 \mathrm{a}$ is the microhardness curve of the bionic unit along the $\mathrm{X}$-axis direction, and Figure $9 \mathrm{~b}$ is the microhardness curve of the bionic unit along the $\mathrm{Y}$-axis direction. Figure $9 \mathrm{a}, \mathrm{b}$ show that the hardness of the remelting zone and the HAZ of the biomimetic unit are higher than those of the matrix, and the hardness of the bionic unit is gradually increased as the carbon content increases. This also echoes the microstructure changes in Figure 7. After calculation, the average hardness of the bionic unit after laser fusion treatment is 321, 343, 466, 493, and $659 \mathrm{HV}$. The degree of hardness improvement is $155 \%, 89 \%, 86 \%, 83 \%$, and $106 \%$, relative to the respective matrix.
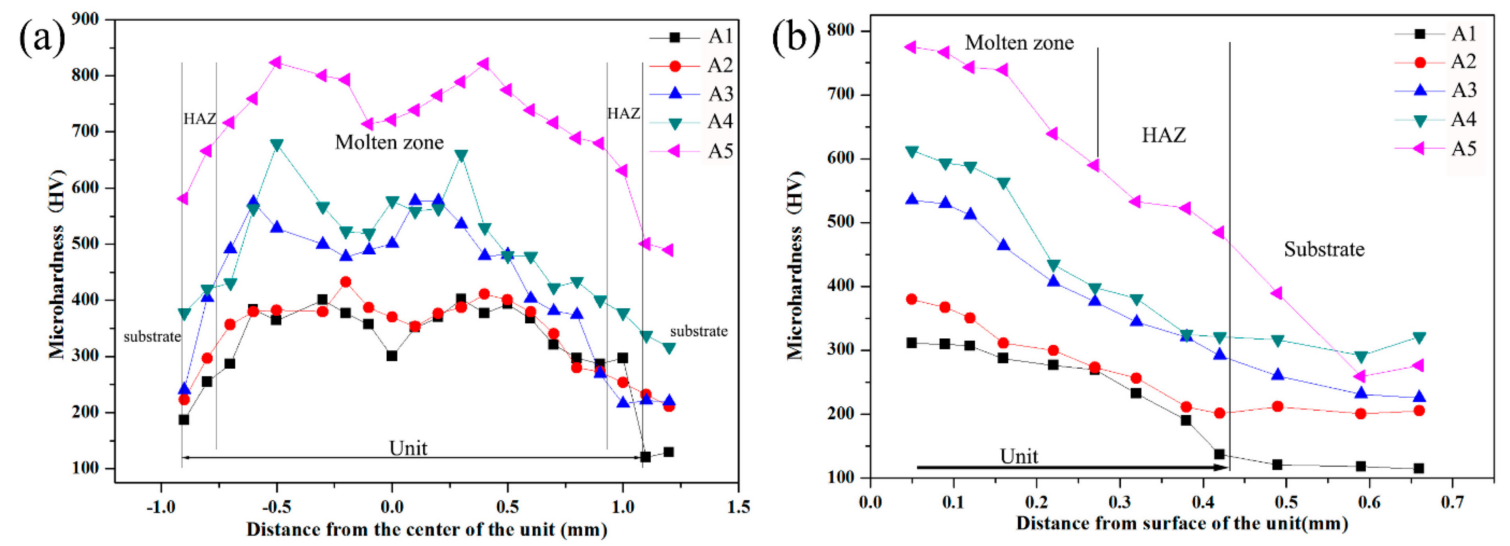

Figure 9. The hardness of the biomimetic unit: (a) section profile along the $X$-axis and (b) section profile along the $Y$-axis.

\subsubsection{Tensile Properties of Specimens}

To compare the tensile properties of the samples with different carbon contents after laser bionic treatment, the bionic units with the same volume proportions were processed on the surface of the base material. The effect of carbon content on the tensile properties of the biomimetic samples was investigated. Figure 10a-e shows the stress-strain curves of the different carbon-containing untreated samples and laser bionic samples; the corresponding yield strength (YS), tensile strength (TS), and elongation (EL) are shown Table 4.To compare the tensile properties of each biomimetic sample, the tensile property improvement ratio [28] is used to analyze the strengthening effect of different biomimetic samples. The tensile property change ratio refers to the percentage of yield strength, tensile strength, and elongation change of the biomimetic sample compared to the untreated sample, which are represented by $Y S C, T S C$, and $E L C$, respectively. 


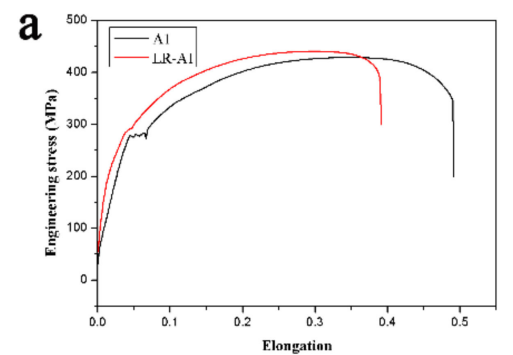

d

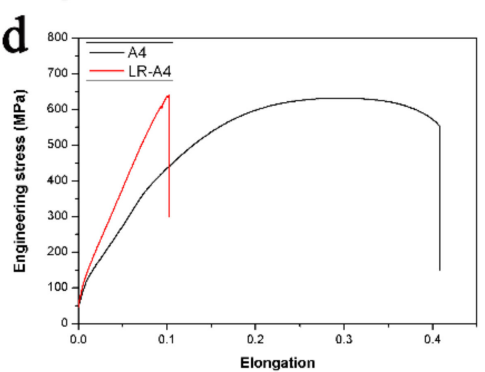

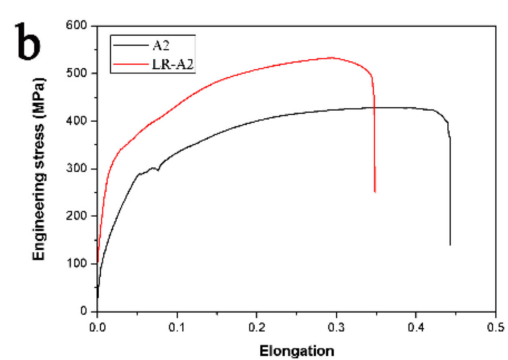

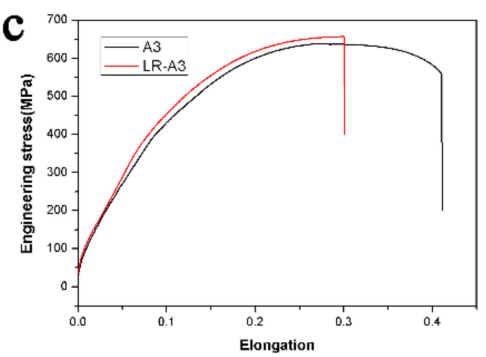

e

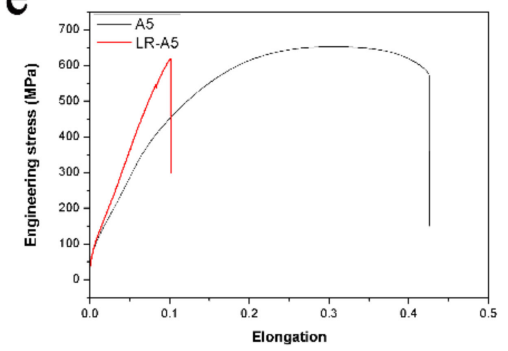

Figure 10. Tensile curves of bionic samples and untreated samples with different carbon contents: (a) A1, (b) A2, (c) A3, (d) A4, and (e) A5.

Table 4. Tensile test results of the bionic treatment samples and untreated samples.

\begin{tabular}{|c|c|c|c|c|c|c|c|c|c|}
\hline \multirow{2}{*}{ Groups } & \multicolumn{2}{|c|}{ YS (MPa) } & \multirow{2}{*}{$\begin{array}{c}\text { YSC } \\
(\%)\end{array}$} & \multicolumn{2}{|c|}{ TS (MPa) } & \multirow{2}{*}{$\begin{array}{c}\text { TSC } \\
(\%)\end{array}$} & \multicolumn{2}{|c|}{ EL (\%) } & \multirow{2}{*}{$\begin{array}{c}\text { ELC } \\
(\%)\end{array}$} \\
\hline & Untreated & Treated & & Untreated & Treated & & Untreated & Treated & \\
\hline A1 & 275 & 342 & 24.36 & 428 & 440 & 2.80 & 39 & 19 & -34.48 \\
\hline $\mathrm{A} 2$ & 285 & 387 & 35.79 & 440 & 532 & 20.91 & 24 & 14 & -41.67 \\
\hline A3 & 295 & 390 & 32.20 & 636 & 656 & 3.14 & 21 & 10 & -52.38 \\
\hline $\mathrm{A} 4$ & 268 & & & 631 & 639 & 1.26 & 18 & 3 & -83.33 \\
\hline A5 & 414 & & & 652 & 618 & -5.21 & 15 & 2 & -86.67 \\
\hline
\end{tabular}

From Figure 10 and Table 4, it can be concluded that when the carbon content is in the range of $0.15-0.37 \%$, the bionic sample shows a ductile fracture, and when the carbon content is in the range of $0.45-0.58 \%$, the bionic sample shows a brittle fracture. When the carbon content is in the range of $0.15-0.37 \%$, the tensile strength and yield strength of the samples after laser biomimetic treatment are better improved compared to the untreated sample. However, the tensile strength of the bionic samples with carbon content in the range of $0.45-0.58 \%$ decreased, especially the tensile strength of the bionic sample with a carbon content of $0.58 \%$, which is even lower than that of the untreated sample.

Figure 11 shows a comparison of the tensile curve of bionic samples with different carbon contents. It can be seen that when the carbon content is between $0.15 \%$ and $0.37 \%$, the strength of the biomimetic sample increases, and when the carbon content increases to $0.45 \%$, the tensile strength begins to decline. The elongation of the biomimetic samples decreases continuously with increasing carbon content. 


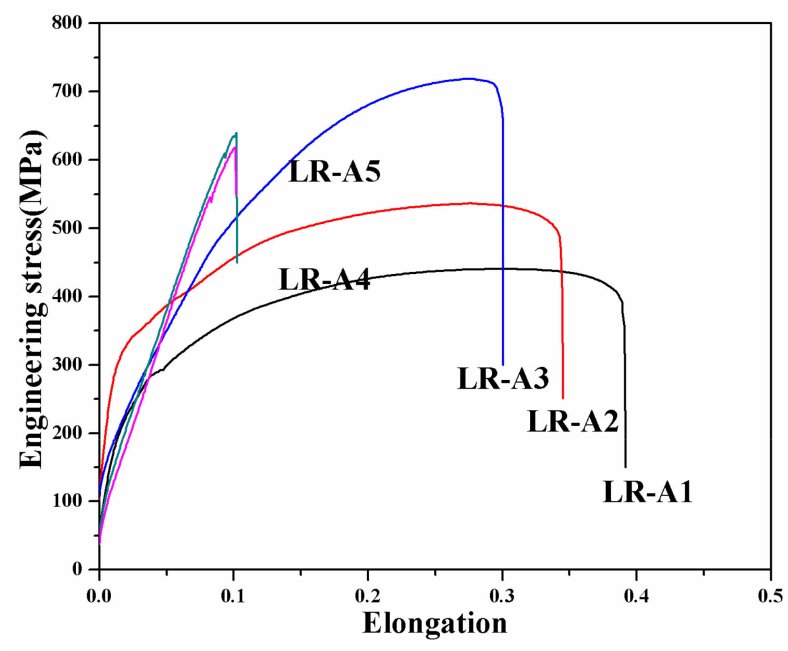

Figure 11. Comparative tensile curves of different bionic samples.

\subsubsection{Tensile Fracture Morphology of Samples}

Figure 12a-e shows the fracture morphology of untreated samples with different carbon contents. After plastic deformation, dimples and tearing ridges appear in the fracture of the sample. Furthermore, as the carbon content increases, the number of dimples increases, indicating that the strength of the samples also increase.
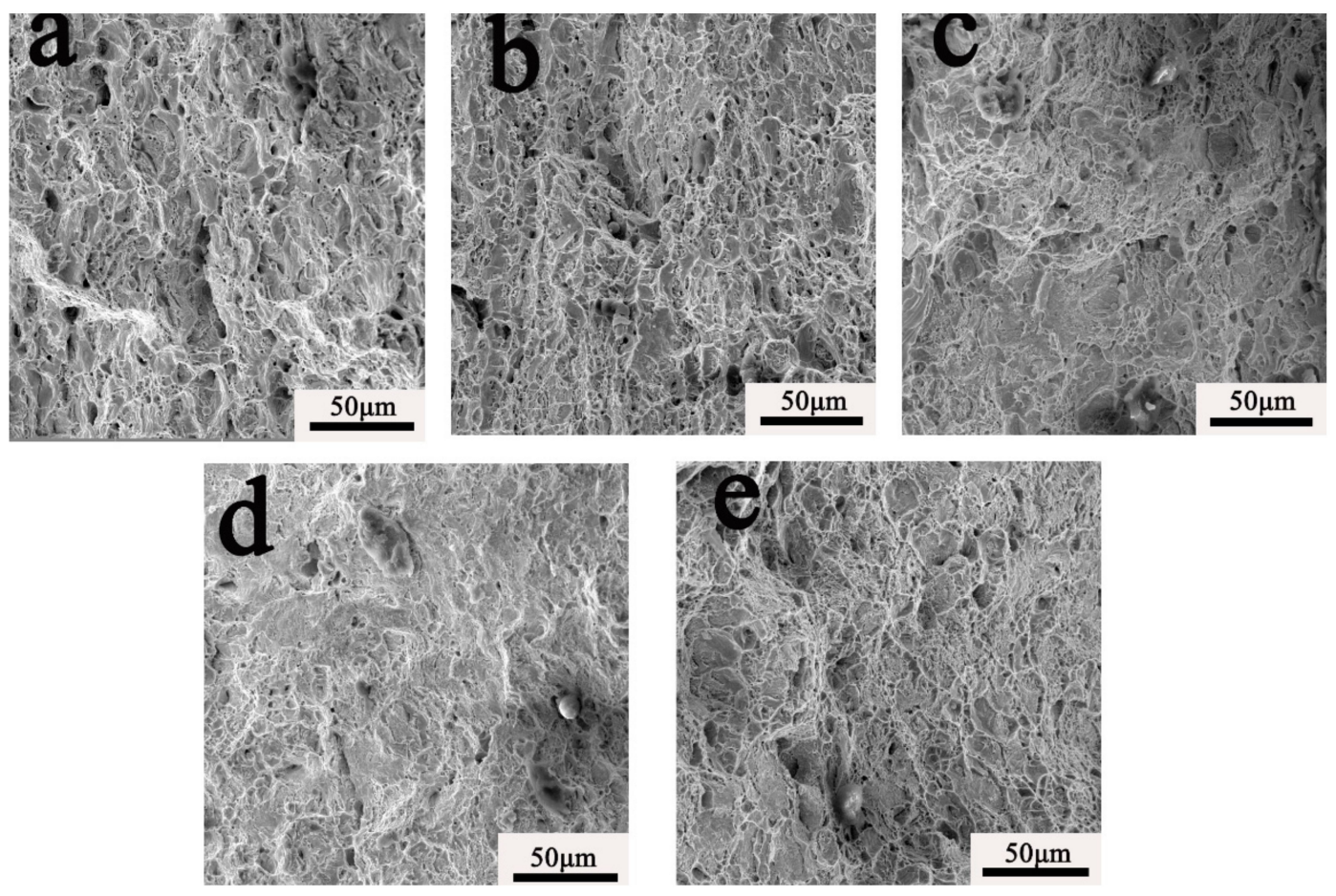

Figure 12. Fracture surfaces of the untreated samples: (a) A1, (b) A2, (c) A3, (d) A4, and (e) A5.

Figure 13a-e shows the fracture morphologies of the units. It can be seen that the fracture morphologies are different from those of the untreated samples. When the carbon content is between $0.15 \%$ and $0.37 \%$, more dimples appear in the fracture of the bionic unit, and the dimples become smaller and deeper. Furthermore, as the carbon content increases, the dimples gradually decrease. For the tensile properties of the specimen, the smaller and deeper the dimple, the more energy required to break the sample. When the carbon content is $0.37 \%$, tearing ridges and cleavage planes appear at 
the fracture of the biomimetic unit, indicating that the sample has a brittle fracture tendency. When the carbon content increases to $0.45-0.55 \%$, the sample experiences a brittle fracture, and the fracture morphology has obvious tearing ridges, cleavage step, and a river pattern, further verifying that the tensile properties are inferior.
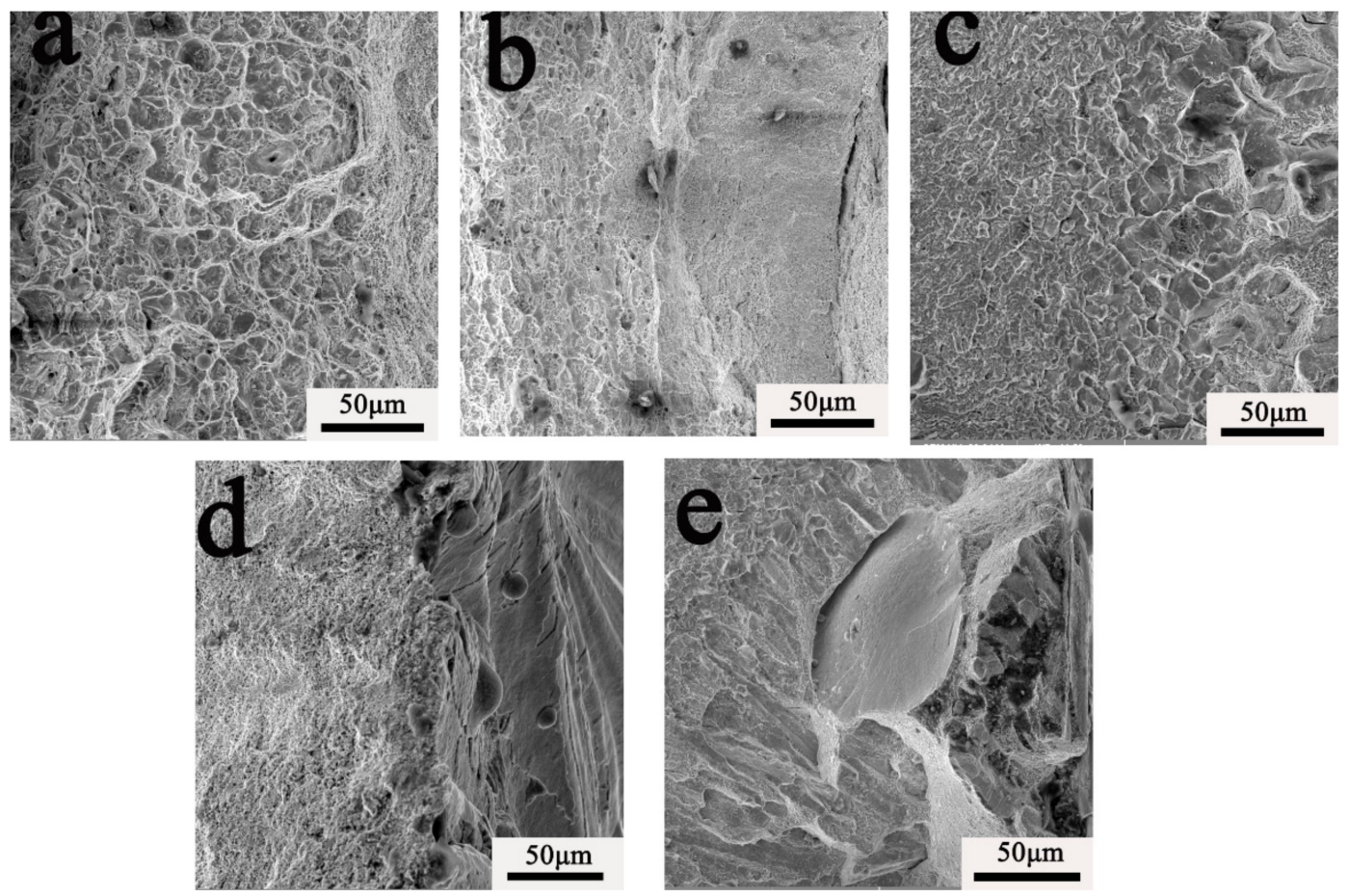

Figure 13. Fracture surfaces of the units: (a) LR-A1, (b) LR-A2, (c) LR-A3, (d) LR-A4, and (e) LR-A5.

\subsection{Wear Properties of Samples}

\subsubsection{Analysis of Wear Loss}

To compare the wear performance of the samples with different carbon content after laser biomimetic treatment, the biomimetic unit with the same volume proportions was processed on the surface of the base metal. The effect of carbon content on the wear properties of the bionic samples was studied. Figure 14 shows the weight loss of the bionic samples and untreated samples with different carbon content. It can be seen that the wear loss weight of the laser biomimetic samples is significantly reduced compared to that of the untreated samples. To compare the antiwear properties of the biomimetic samples, the weight loss reduction percentage [29] (WLRP) is defined, as shown in Equation (2):

$$
\mathrm{WLRP}=\frac{W L_{\text {Untreated }}-W L_{\text {treated }}}{W L_{\text {Untreated }}} \times 100 \%
$$

where $W L_{\text {Untreated }}$ is the wear-loss weight of the untreated sample, and $W L_{\text {Treated }}$ is the wear-loss weight of the treated sample.

The WLRP order of the laser biomimetic samples with different carbon content is: LR-A1 (31.01\%) $<$ LR-A2 $(31.72 \%)<$ LR-A3 (36.08\%) < LR-A4 (48\%) < LR-A5 (67.76\%). This order is due to the different hardness between the materials leading to differences in wear resistance. When the hardness of the sample is higher, the wear resistance is better, and the wear loss is smaller. 


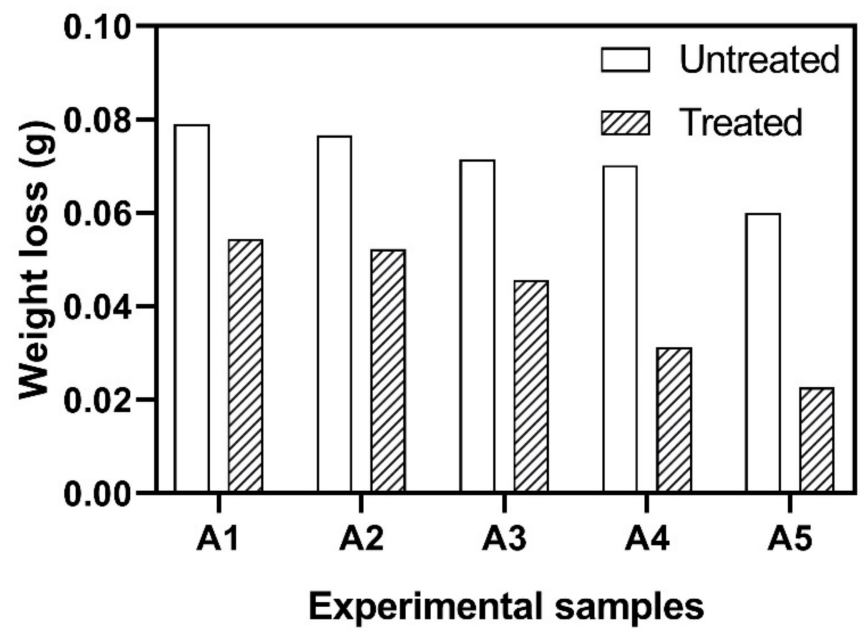

Figure 14. Mass loss of samples.

\subsubsection{Analysis of Wear Morphology}

Figure 15a-e shows the wear morphology of the untreated samples with different carbon content. It can be seen that a large amount of spalling and deep furrows occurs during the wear process, especially when the carbon content is low. Therefore, the main wear forms of the untreated sample are adhesive wear and abrasive wear.
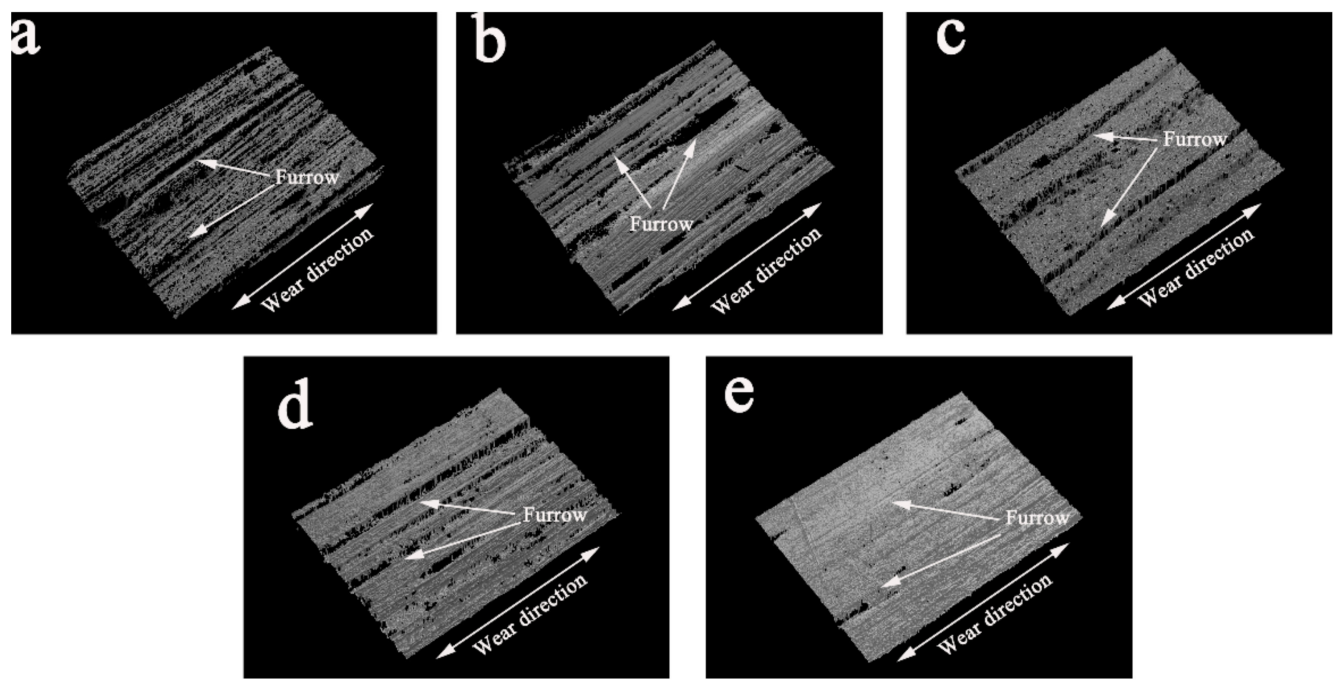

Figure 15. Wear morphology of the untreated samples: (a) A1, (b) A2, (c) A3, (d) A4, and (e) A5.

Figure 16a-e shows the wear morphology of the laser biomimetic samples with different carbon content. Compared with the wear morphology of the untreated sample, it can be seen in the difference between the unit and the matrix that the unit does not have large peeling or deep furrow phenomena, indicating that the wear resistance of the unit is better than that of the matrix. By comparing the wear morphology of LR-A1-LR-A5, it can be seen that the density and depth of the furrows on the units also gradually reduced, indicating that with an increase of carbon content, the wear resistance of the laser biomimetic samples also gradually improves. This process corresponds to the weight loss and the hardness of the unit. 

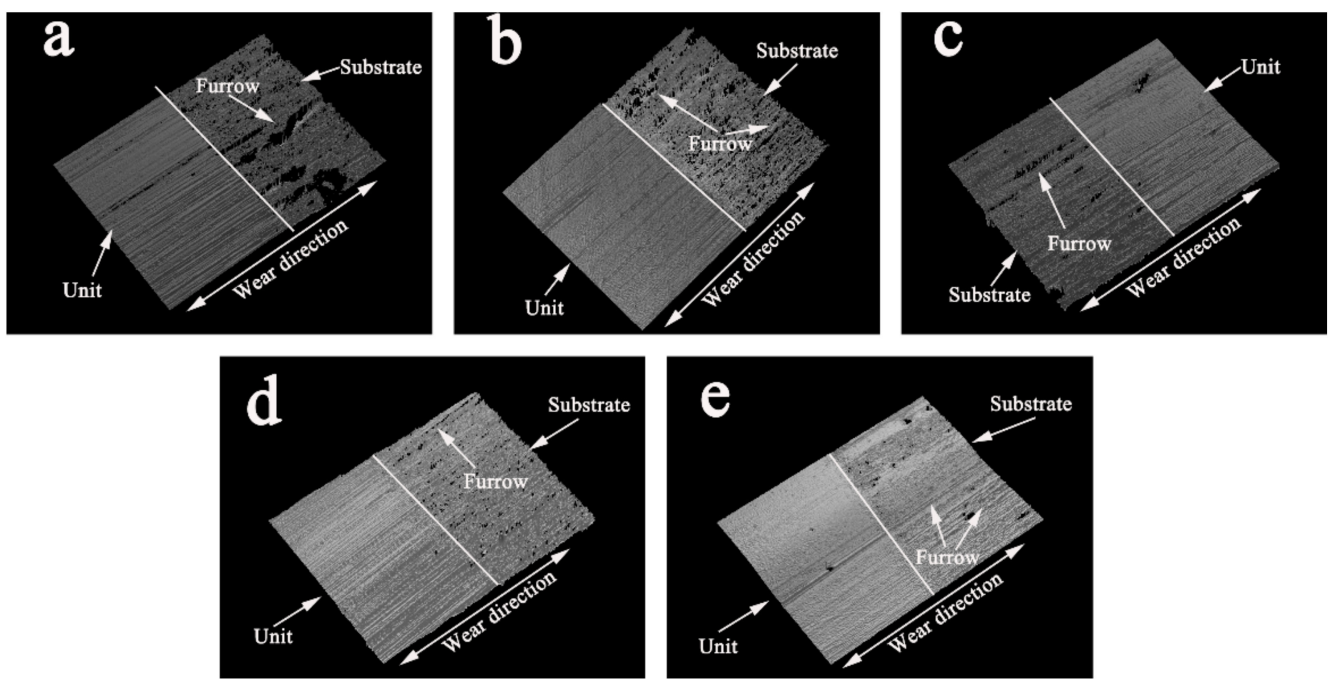

Figure 16. Wear morphology of the bionic samples: (a) LR-A1, (b) LR-A2, (c) LR-A3, (d) LR-A4, and (e) LR-A5.

\section{Conclusions}

In this paper, the effects of carbon content on the characteristics, microstructure, hardness, and properties of the bionic unit were studied, and the response of the base material, with different compositions, to laser bionic treatment was obtained. The conclusions are as follows:

1. The unit characteristics (depth and width) are affected by the laser parameters and the parent material's composition. When the laser processing parameters are constant, the unit characteristics increase as the carbon content increases. The order of the unit characteristics is LR-A1 $<$ LR-A2 $<$ LR-A3 < LR-A4 < LR-A5.

2. Under the same laser processing parameters, the microstructure of the remelting zone with different carbon content is the same-composed of martensite. With an increase of carbon content, the content of lath martensite decreases, and the content of plate martensite increases, which increases the hardness of the biomimetic unit.

3. Compared with untreated samples, the tensile strength of the biomimetic sample with the same volume fraction of the unit increases when the carbon content is $0.15-0.45 \%$; when the carbon content is higher than 0.45 , the tensile strength is reduced. For laser biomimetic samples, as the carbon content increases, the tensile strength of the biomimetic sample first increases and then decreases, while the plasticity decreases. the degree of improvement in tensile strength is LR-A5 $<$ LRA-4 $<$ LR-A1 $<$ LR-A3 $<$ LR-A2; the degree of plasticity reduction is LR-A1 $<$ LR-A2 $<$ LR-A3 $<$ LR-A4 $<$ LR-A5.

4. Compared to the untreated samples, the wear resistance of the bionic specimens with the same volume fraction of the unit shows better improvement. For the laser biomimetic samples, as the carbon content increases, the wear resistance increases.

5. This study indicates the application feasibility of laser remelting strengthening for different carbon steel parts in manufacturing industry.

Author Contributions: G.C. Study design, Data collection, Data analysis, Writing; T.Z. Literature search. H.Z. Study design; P.Z. Study design, Literature Search; S.M. Data analysis; B.Z. Literature search; S.W.: Data analysis. All authors have read and agreed to the published version of the manuscript.

Funding: This work was supported by Project 985-High Performance Materials of Jilin University, Project 985-Bionic Engineering Science and Technology Innovation, and the double first-class project by Jilin Province and Jilin University (SXGJXX2017-14), Natural Science Foundation of Liaoning Province (No. 20170540421) and National Natural Science Foundation of China (U1601203). 
Conflicts of Interest: It is submitted to be considered for publication as an "Original research work" in your journal. This paper is new. Neither the entire paper nor any part of its content has been published or has been accepted elsewhere. It is not being submitted to any other journal. And there is no conflict of interest in this article.

\section{References}

1. Ruys, A. 10-Alumina in bionic feedthroughs: The bionic eye and the future. In Alumina Ceramics; Ruys, A., Ed.; Woodhead Publishing: Cambridge, UK, 2019; pp. 283-319.

2. Safyannikov, N.M.; Bureneva, O.I.; Aleksanyan, Z.A. Non-invasive Method of Intelligent Sensory Control of Hands' Motor Functions for Bionic Systems. Procedia Comput. Sci. 2019, 150, 333-339. [CrossRef]

3. Wu, J.; Ma, G. Imitation of nature: Bionic design in the study of particle adjuvants. J. Controll. Release 2019, 303, 101-108. [CrossRef] [PubMed]

4. Zhang, T.; Wang, A.; Wang, Q.; Guan, F. Bending characteristics analysis and lightweight design of a bionic beam inspired by bamboo structures. Thin Walled Struct. 2019, 142, 476-498. [CrossRef]

5. Wang, J.; Cheng, C.; Zeng, X.; Zheng, J.; Zhou, Z. Bionic-tribology design of tooth surface of grinding head based on the bovine molar. Tribol. Int. 2020, 143, 106066. [CrossRef]

6. Rajabi, H.; Moghadami, M.; Darvizeh, A. Investigation of microstructure, natural frequencies and vibration modes of dragonfly wing. J. Bionic Eng. 2011, 8, 165-173. [CrossRef]

7. Ren, L.; Li, X. Functional characteristics of dragonfly wings and its bionic investigation progress. Sci. China Technol. Sci. 2013, 56, 884-897. [CrossRef]

8. Huang, H.; Zhang, Y.; Ren, L. Particle Erosion Resistance of Bionic Samples Inspired from Skin Structure of Desert Lizard, Laudakin stoliczkana. J. Bionic Eng. 2012, 9, 465-469. [CrossRef]

9. Jagota, A.; Hui, C.Y. Adhesion, friction, and compliance of bio-mimetic and bio-inspired structured interfaces. Mater. Sci. Eng. R Rep. 2011, 72, 253-292. [CrossRef]

10. Kamat, S.; Su, X.; Ballarini, R.; Heuer, A.H. Structural basis for the fracture toughness of the shell of the conch Strombus gigas. Nature 2000, 405, 1036-1040. [CrossRef]

11. Meldrum, F.C.; Cölfen, H. Controlling mineral morphologies and structures in biological and synthetic systems. Chem. Rev. 2008, 108, 4332-4432. [CrossRef]

12. Etsion, I. State of the art in laser surface texturing. J. Tribol. 2005, 127, 248-253. [CrossRef]

13. Kannatey-Asibu, E. Principles of Laser Materials Processing; John Wiley \& Sons: Hoboken, NJ, USA, 2008; pp. 1-819.

14. Mazumder, J.; Steen, W.M. Heat transfer model for cw laser material processing. J. Appl. Phys. 1980, 51, 941-947. [CrossRef]

15. Meijer, J. Laser beam machining (LBM), state of the art and new opportunities. J. Mater. Proc. Technol. 2004, 149, 2-17. [CrossRef]

16. Shi, W.; Wang, P.; Liu, Y.; Han, G. Experiment of Process Strategy of Selective Laser Melting Forming Metal Nonhorizontal Overhanging Structure. Metals 2019, 9, 385. [CrossRef]

17. Yu, Y.; Zhang, M.; Guan, Y.; Wu, P.; Chong, X.; Li, Y.; Tan, Z. The Effects of Laser Remelting on the Microstructure and Performance of Bainitic Steel. Metals 2019, 9, 912. [CrossRef]

18. Zhang, Y.; Guo, Y.; Chen, Y.; Kang, L.; Cao, Y.; Qi, H.; Yang, S. Ultrasonic-Assisted Laser Metal Deposition of the Al 4047Alloy. Metals 2019, 9, 1111. [CrossRef]

19. Kurella, A.; Dahotre, N.B. Review paper: Surface modification for bioimplants: The role of laser surface engineering. J. Biomater. Appl. 2005, 20, 5-50. [CrossRef]

20. Li, C.; Yang, L.J.; Yan, C.C.; Chen, W.; Cheng, G.H. Biomimetic anti-adhesive surface micro-structures of electrosurgical knife fabricated by fibre laser. J. Laser Micro Nanoeng. 2018, 13, 309-313.

21. Yu, D.; Zhou, T.; Zhou, H.; Bo, H.; Lu, H. Non-single bionic coupling model for thermal fatigue and wear resistance of gray cast iron drum brake. Opt. Laser Technol. 2019, 111, 781-788. [CrossRef]

22. Yuan, Y.; Zhao, G.; Zhang, P.; Zhou, H. Effects of shapes of biomimetic coupling units on wear resistance of 7075 aluminum alloy. Opt. Laser Technol. 2020, 121, 105786. [CrossRef]

23. Ji, M.; Xu, J.; Chen, M.; El Mansori, M. Enhanced hydrophilicity and tribological behavior of dental zirconia ceramics based on picosecond laser surface texturing. Ceram. Int. 2019, 30, 106-116. [CrossRef] 
24. Meng, C.; Zhou, H.; Tong, X.; Cong, D.L.; Wang, C.W.; Ren, L.Q. Comparison of thermal fatigue behaviour and microstructure of different hot work tool steels processed by biomimetic couple laser remelting process. Mater. Sci. Technol. 2013, 29, 496-503. [CrossRef]

25. Zang, C.; Zhou, T.; Zhou, H.; Yuan, Y.; Zhang, P.; Meng, C.; Zhang, Z. Effects of substrate microstructure on biomimetic unit properties and wear resistance of $\mathrm{H} 13$ steel processed by laser remelting. Opt. Laser Technol. 2018, 106, 299-310. [CrossRef]

26. Wang, W.; Kodur, V. Chapter 2-Thermal properties of steel at elevated temperature. In Material Properties of Steel in Fire Conditions; Wang, W., Kodur, V., Eds.; Academic Press: Cambridge, MA, USA, 2020; pp. $29-41$.

27. Epp, J. 4-X-ray diffraction (XRD) techniques for materials characterization. In Materials Characterization Using Nondestructive Evaluation (NDE) Methods; Hübschen, G., Altpeter, I., Tschuncky, R., Herrmann, H.-G., Eds.; Woodhead Publishing: Cambridge, UK, 2016; pp. 81-124.

28. Wang, C.; Zhou, H.; Liang, N.; Wang, C.; Cong, D.; Meng, C.; Ren, L. Mechanical properties of several laser remelting processed steels with different unit spacings. Appl. Surf. Sci. 2014, 313, 333-340. [CrossRef]

29. Su, W.; Zhou, T.; Zhang, P.; Zhou, H.; Li, H. Effect of distribution of striated laser hardening tracks on dry sliding wear resistance of biomimetic surface. Opt. Laser Technol. 2018, 98, 281-290. [CrossRef]

(C) 2019 by the authors. Licensee MDPI, Basel, Switzerland. This article is an open access article distributed under the terms and conditions of the Creative Commons Attribution (CC BY) license (http://creativecommons.org/licenses/by/4.0/). 